\title{
Optimization modelling for environment pollution mitigation as a result of energy activities in Tanzania
}

\author{
Regobert C. Ngeleja1 ${ }^{1}$ Padmanabhan Seshaiyer ${ }^{2}$ and Halidi A. Lyeme ${ }^{3}$ \\ ${ }^{1}$ Dar es Salaam Institute of Technology, Dar es Salaam, Tanzania \\ ${ }^{2}$ Mathematical Science Department, George Mason University, USA \\ ${ }^{3}$ Department of Mathematics, Muslim University of Morogoro, Tanzania
}

Received: 3 June 2020, Accepted: 27 December 2020

Published online: 21 March 2021.

\begin{abstract}
Energy is essential in supporting people's daily lives and the continual quest for human development. Energy harvesting, production, distribution, and consumption have major environmental implications some of which are negative and the other positive. Insults include deforestation, land degradation and emission of GHG due to energy activities (harvesting, production and consumption) which has harmful effects to the natural as well as human environment but the greatest important abuse from energy systems is the repetitive and unintended release of pollutants. In this study the mathematical model for minimization of environmental pollutants caused by energy harvesting, production and consumption were presented. The objective of our study is to provide a model solution that will minimize the environment pollutant for Tanzania to achieve her development vision 2025 sustainably with clean and safe environment. The problem is solved as a linear programming problem using Zimmerman modified method algorithm and yield the solution by considering the fuzzy nature of the data in the model.
\end{abstract}

Keywords: Tanzania development Vision 2025, Environment pollutant, Optimization Modeling, Zimmerman modified method, fuzzy.

\section{Introduction}

The increasing threat of global warming and climate change has focused attention on the relationship between energy and environment. Throughout human history, most direct human energy needs are derived from combustion from solids fuels, solid fuels require relatively advanced technology to be pre-mixed with air or otherwise ensure their complete combustion [1].The airborne emissions of incomplete combustion products, such as carbon monoxide, particulates, and volatile organic compounds, are increasing significantly as the need for energy increase.Energy use and supply is of fundamental importance to society, and has made the greatest impact on promoting the development of the society and the world at large. But due to the increase and the pervasive nature of energy related activities it has lead to different environmental problems [2].

\subsection{Energy Sector in Tanzania}

Tanzania has various number of energy sources including solar, wind, biogas, natural gas, hydropower, biofuel, coal reserves, wood fuel, and geothermal power. Among all these, the most exploited source is wood fuel since it is considered both cheap and easily reached by the majority poor in rural and urban areas [3]. The energy balance of Tanzania displays that biomass (in form of firewood, charcoal and agricultural waste) usage accounts for more than $90 \%$ of energy consumption. Petroleum account for $8 \%$, electricity for $1.2 \%$ and the remaining $0.8 \%$ coming from coal and other renewable energies [4]. Petroleum is imported and the transport sector is the main consumer of petroleum products. Currently, only $70 \%$ of the demand for petroleum is met. However natural gas, which is available, is to be the possible 


\section{Total current energy usage in Tanzania}

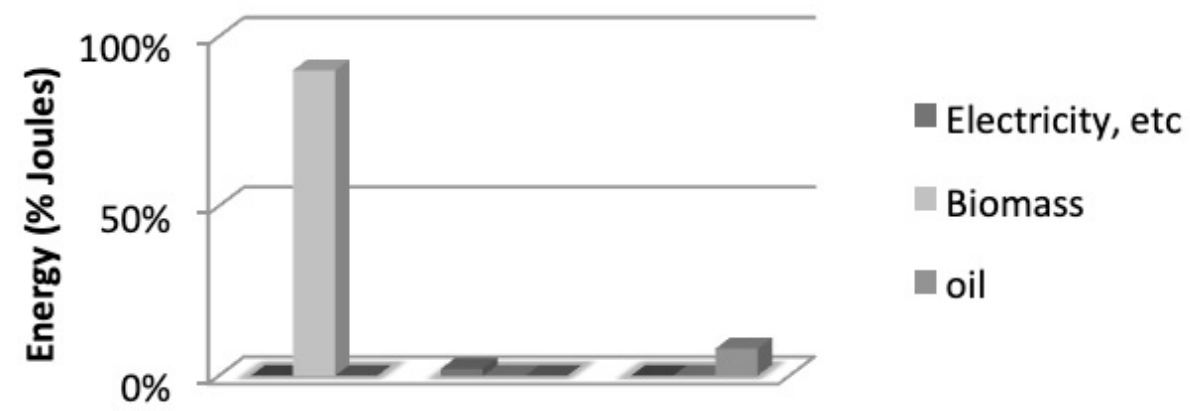

Fig. 1: The current energy balance in Tanzania

substitute for oil though the main hindrances of its use is basically capital and lack of technology to extract gas and use it for various energy purposes [5]. There are also other indigenous substitute sources of energy that include coal, solar and wind. Most of these sources of energy are not fully utilized and the main reason is lack of capital. Tanzania has 1,200 million metric tons of coal, which could make available energy for paper mills, cement industries, agriculture and household consumption, and for generation of electricity. Wind and solar energy is another source of energy. Very little attempt has been made to utilize this source of energy that could be a viable substitute source to reduce use of oil and wood for heating purposes. Recently the country is investigating on the possibility of using nuclear power as a source of energy [6].

Electricity is mostly generated from hydropower, which is disposed to draught effects, so some thermal power stations have been installed. There are plans to connect with neighboring countries like Uganda and Zambia to the national grid to increase the supply of electricity [7].

Tanzania's per capita electricity consumption of 46/KWh per year and it grows at the rate of $11 \%-13 \%$. Hence, the government is inspiring investment to expand generating capacity, supply system and developing local sources of energy [8]. Due to the fact that lack of access to adequate and viable supplies of energy affects as much as $90 \%$ of the population of many third world countries. According to the World Bank report (2018), only $32.8 \%$ of the populations in Tanzania have access to electricity, of which urban areas have more access $(65.3 \%)$ to electricity and only (16.9\%) for the rural areas. Short of efficient, clean energy, people are demoralized in their efforts to involve effectively in productive activities or to improve their quality of life [9].

\subsection{Improving Access to Energy in Tanzania}

As a result of significant population growth (presently 44 million, projected to rise to 55 million for the next 5 years, of which only $10.5 \%$ is connected to the national power grid at present) and continued economic growth (real GDP for 2012 was 7.04\%) Tanzania?s energy demand is projected to grow by between 5 and $8.5 \%$ per year for the next 5 years. To surplus this energy demand Tanzania's power sector needs significant new investment to develop greater power generation diversification and upgrade and expand the transmission and distribution network. Knowing the importance of energy in the development process, Tanzania completed a policy for ensuring obtainability of reliable and reasonably priced energy supplies and their use in a rational and viable manner in order to support national development objectives $[10]$. 
Chances for new power generation are rich, such as by hydropower generation, gas and coal which are expected to increase. Tanzania calls for establishment of a well-organized energy production, transportation, distribution, procurement and end-use systems in a sustainable manner [11].

\subsection{Energy and Environment}

The development of science and technology has altered the world in countless ways. It has, on the other hand led to developments of environmental problems that threaten man and nature. For the duration of the past two decades, the risk and reality of environmental problems have become more evident. Increasing evidence of environmental problems is due to a mixture of quite a lot of factors, the leading factor being energy, in the whole process of harvesting, production and consumption [12]. The environmental impacts have grown dramatically as world populations? raise, many faster than the average of $2 \%$, the need for more and more energy is worsen. Improved lifestyle and increased energy demand and the wealthy developed economics, which comprise $25 \%$ of the world?s population, consume $75 \%$ of the world?s energy supply [13]. In recent times, environmental concerns have prolonged to land degradation (soil erosion), deforestation and hazardous air pollutants [14]. The world?s energy consumption today is likely to be 22 billion kWh per annum. Approximately 6.6 billion metric tons carbon equivalent of green-house gas (GHG) emission are released in the atmosphere to surplus this energy demand [15]. About $80 \%$ is due to carbon emissions from the combustion of energy fuels. By [16] because of energy?s ubiquity and size, energy activities (harvesting, production and consumption) influence almost every category of environmental insult and impacts as seen in the relational diagram below:

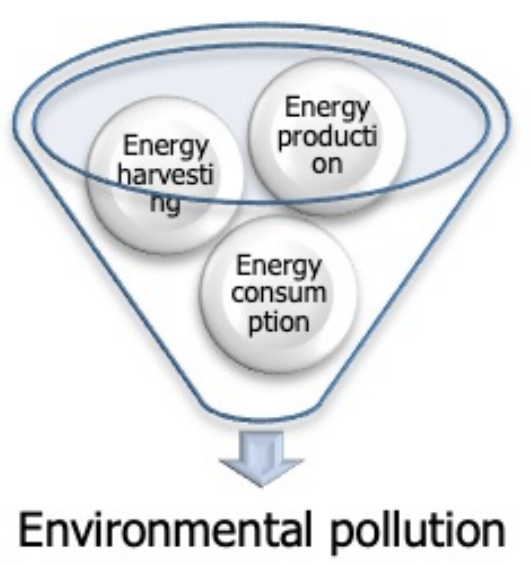

Fig. 2: Relationship between energy activities and environment

\section{Model formulation}

\subsection{Problem identification}

As there is rapid growth in global population and industrialization and the rate is constantly growing the energy demand will also increase proportionally then getting the energy we need to disturb our environment in many diverse ways [17]. Some energy sources have a greater impact than others, so in order to meet the mankind?s need in terms of environment safety one should find the way that will change the composition of energy system in Tanzania in such a way that it does not affect the environment. Different energy activities yield significant number of negative effect to the environment and 
these effects are emissions of air pollutants like sulphur oxides $\mathrm{SO}_{x}$, nitrogen oxides $\mathrm{NO}_{x}$ and carbon dioxide $\mathrm{CO}_{2}$ together with land degradation (Deforestation) [18].

Therefore, minimization of the environment pollution caused by different energy activities as the energy demand increases is the purpose of this study. The output will allow Tanzania to realize her development vision 2025 in environmental friendly manner.

\subsection{Variables and their description}

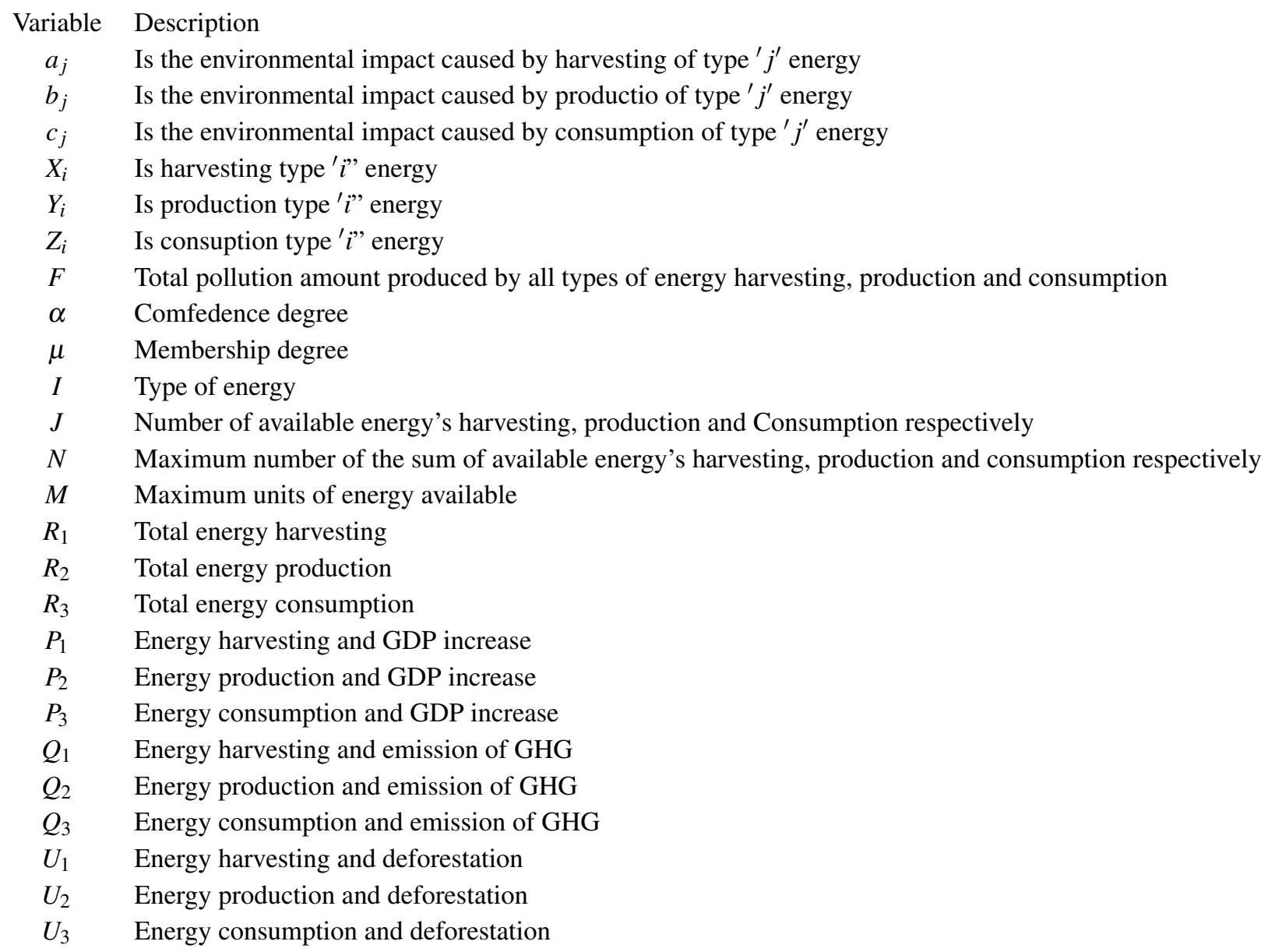

\subsection{Modeling}

The linear model for minimization of environment pollutant is as given below; Minimize environmental negative impact

$$
\operatorname{Min} F=\sum_{i=1}^{m} \sum_{j=1}^{m}\left(a_{j} X_{i}+b_{j} Y_{i}+c_{j} Z_{j}\right)
$$


subject to;

$$
\left\{\begin{array}{l}
R_{3} \leq R_{2} \\
D_{k} \geq d_{k} \\
U_{k} \geq u_{k} \\
Q_{k} \geq q_{k} \\
R_{k} \geq r_{k} \\
X_{i}(t) \geq 0 \\
Y_{i}(t) \geq 0 \\
Z_{i}(t) \geq 0
\end{array}\right.
$$

${ }^{\prime} i$ 'Represent energy units, ${ }^{\prime} k$ 'represent energy processes (Harvesting, Production and Consumption)

Where $F$ is the total environmental impact produced by all types of energy harvesting, production and consumption $a_{j}, b_{j}$ and $c_{j}$ are pollution produced by energy harvesting, production and consumption respectively $X_{i}$ represent harvesting of type ' $i$ ' energy, $Y_{i}$ represent production of type ' $i$ ' energy $Z_{i}$ represent consumption of type ' $i{ }^{\prime}$ energy, i= Type of energy, $D$ represent the lower compound GDP growth, $U$ is a lower compound deforestation increase, $Q$ is a lower compound $G H G$ emission, $R_{1}$ is the amount of energy harvested, $R_{2}$ is the amount of energy produced, $R_{3}$ is the of energy to be consumed.

In a real situation, decision makers do not have precise and comprehensive information related to decision criteria and constraints [19]. In our case of the environmental pollutant minimization problem the collected information does not behave crisply and they are typically fuzzy in nature. Then the fuzzy approach is used to solve the environmental pollutant minimization model.

As the relevant data are uncertain and we lack the original data source, data are obtained by logical reasoning by considering what is real happening and the experts? judgments and thus, the data are quite fuzzy, called fuzzy numbers. Therefore, in order to minimize environmental pollutants, we have;

$$
\operatorname{Min} F=\sum_{i=1}^{m} \sum_{j=1}^{m}\left(a_{j} X_{i}+b_{j} Y_{i}+c_{j} Z_{j}\right)
$$

We can write the above function in matrix form as given below

$$
\operatorname{Min} F=\left[\begin{array}{llll}
a_{1} \ldots a_{6} & b_{1} \ldots b_{6} & c_{1} \ldots c_{6}
\end{array}\right]\left[\begin{array}{c}
x_{1} \\
\vdots \\
x_{6} \\
y_{1} \\
\vdots \\
y_{6} \\
z_{1} \\
\vdots \\
z_{6}
\end{array}\right]
$$

Where $\left(a_{1} \ldots a_{6} b_{1} \ldots b_{6} \quad c_{1} \ldots c_{6}\right)$ are the positive values which represent negative environmental impacts (pollution) contributed by each energy unit in every energy 's process. In this study by considering the proportional of the trend of production, consumption and harvesting the pollutant of eachenergy's activities are as summarized in the following expression: 


$$
\begin{array}{r}
\operatorname{Min} F_{1}=a_{1}\left((1-\alpha) x_{1}+\alpha x_{1}\right)+a_{2}\left((1-\alpha) x_{2}+\alpha x_{2}\right)+a_{3}\left((1-\alpha) x_{3}+\alpha x_{3}\right)+a_{4}\left((1-\alpha) x_{4}+\alpha x_{4}\right) \\
+a_{5}\left((1-\alpha) x_{5}+\alpha x_{5}\right)+a_{6}\left((1-\alpha) x_{6}+\alpha x_{6}\right)+b_{1}\left((1-\alpha) y_{1}+\alpha y_{1}\right)+b_{2}\left((1-\alpha) y_{2}+\alpha y_{2}\right) \\
+b_{3}\left((1-\alpha) y_{3}+\alpha y_{3}\right)+b_{4}\left((1-\alpha) y_{4}+\alpha y_{4}\right)+b_{5}\left((1-\alpha) y_{5}+\alpha y_{5}\right)+b_{6}\left((1-\alpha) y_{6}+\alpha y_{6}\right) \\
+c_{1}\left((1-\alpha) z_{1}+\alpha z_{1}\right)+c_{2}\left((1-\alpha) z_{2}+\alpha z_{2}\right)+c_{3}\left((1-\alpha) z_{3}+\alpha z_{3}\right)+c_{4}\left((1-\alpha) z_{4}+\alpha z_{4}\right) \\
+c_{5}\left((1-\alpha) z_{5}+\alpha z_{5}\right)+c_{6}\left((1-\alpha) z_{6}+\alpha z_{6}\right)
\end{array}
$$

\subsection{Objective constraints}

(a) Energy harvesting constraint

The harvesting of energies that has the greater impact to the environment like coal, biomass and oil must not exceed the harvesting of other renewable energies like natural gas, Renewable (wind, solar, geothermal) and electricity in order to reduce the negative effects caused by these energies $x_{1}+x_{5}+x_{6}-x_{2}-x_{3}-x_{4}<0$.

(b) Energy production constraint

The production of non- renewable energies and energy which produce a huge environmental effect to the environment like in its production process like coal, oil and biomass must be smaller than production of renewable energies like natural gas, wind, solar and electricity in order to reduce the environmental effects $y_{1}+y_{5}+y_{6}-y_{2}-y_{3}-y_{4}<0$.

(c) Energy consumption constraint

The consumption of energies that has the greater impact to the environment like coal, oil and biomass mast be less than the consumption of other renewable energies like natural gas, wind, solar and electricity in order to reduce the negative effects caused by these energies to the environment $z_{1}+z_{5}+z_{6}-z_{2}-z_{3}-z_{4}<0$.

(d) Multiple GDP growth from various energy processes

The energy demand in Tanzania is increasing very fast as the population increase and the individual and nation introduces different activities (industries, investments) for their development, sectors like agriculture, small and medium industries and domestic uses. This will considerably raise energy processes to counteract the situation and thus increase number of goods produced for consumption, provision of market for several goods and a significant increase of tax payers due to different activities taking place in the same process and thus lead to alternation of GDP in every energy process. According to [20] for Tanzania to move from low income countries to middle income countries as one of the goal of Tanzania development vision 2025 it should have the average annual GDP growth of $8 \%$. Then the GDP produced by all energy?s processes should be greater than or equal to this annual average.

Using SPSS software we use the linear regression analysis to find the relationship between energy harvesting, production and consumption and the GDP then we have

$$
\begin{array}{r}
0.5 x_{1}+9 x_{3}-12405 x_{5}+0.01 x_{6}-3 y_{1}+163.3 y_{2}+26.4 y_{3}-62.7 y_{4}-17129 y_{5} \\
-5 y_{6}-4.5 z_{1}-19.6 z_{2}-2.4 z_{3}+349 z_{4}-5 z_{5}-0.6 z_{6} \geq-16722
\end{array}
$$

(e) A compound deforestation increase from various energy processes

The increase of energy processes (Harvesting, production and Consumption) results tothe increasing demand of energy in the country that led to deforestation. The main considered factor here are the areas where the energy processes are taking place and sometimes the trees are used directly in these processes in some energy unit. The study consider energy harvesting as the only energy process that largely lead to deforestation in Tanzania and ignore the rest of the processes because their contribution to deforestation is very small which is approximately to be zero. By [21] the average annual deforestation rate is 1.93 percent Then the multiple deforestation should be less or equal 
to this increased deforestation in order to reduce the negative impacts that are the result of deforestation.

$$
\begin{array}{r}
x_{6} \leq 1763 \\
296 y_{1}-17740 y_{2}+597 y_{3}-3776 y_{4}-177590 y_{5}+126 y_{6} \leq 134806
\end{array}
$$

(f) A compound GHG emission from various energy processes

Based on the significant increase energy demand and the fact that the three energy processes of different energy unit lead to the production of greenhouse gases thus the increase of the energy processes will automatically lead to the increase of production of greenhouse gases in different stages as energy is processed. The lower compound GHG emission considers the emission caused by all kind of energy in the separate energy process. By [22] the average annual emission rate of Greenhouse gases in metric tons is 0.1 . Then the multiple GHG emission through the different energy processes must be less or equal to this average amount of GHG emission that has negative effect to the environment. Then

$$
\begin{array}{r}
2 x_{1}+56 x_{3}-1560 x_{5}+0.0042 x_{6} \leq-920 \\
2 y_{1}+11 y_{2}+56 y_{3}+4 y_{4}-1905 y_{5}-0.0782 y_{6} \leq-1597 \\
0.12 z_{1}-2.87 z_{2}+0.23 z_{3}-1.49 z_{4}+0.56 z_{5}+0.03 z_{6} \leq 543
\end{array}
$$

(g) The constraint of total energy harvesting

This constraint includes the sum of all annul energy harvested considering the lowest limit and its upper limit when energy is only for basic use and when energy is extended to the economic growth and development respectively. Thus for the proper economic growth that will support both industrial and domestic activities there is a strong need for the sufficient energy harvested to carter the need for proper development then the total energy harvesting should be greater or equal to the average annual energy harvested amount of energy needed in the given period of time. The average total energy harvesting is 22414.3 units of energy. Then;

$$
x_{1}+x_{2}+x_{3}+x_{4}+x_{5}+x_{6} \geq 22414.3
$$

(h) The constraint of total energy production

The total energy production is the annual sum of all energy production with it lower and upper limit. Thus for the proper economic growth that will support both industrial and domestic activities there is a strong need for the sufficient energy production to carter the need of proper development then the total energy produced should be greater or equal to the average annual energy production needed in the given period of time for the proper economic growth. The total energy production should be grater or equal to the estimated amount of energy demand projection in the year 2025, the expected energy demand by the year 2025 is approximated to be 3800MW [23], then:

$$
y_{1}+y_{2}+y_{3}+y_{4}+y_{5}+y_{6} \geq 3800
$$

(i) The constraint of total energy consumption

This is the total annual energy use, and its possible range from the lowest possible capacity (lower limit) to the highest demand (upper limit). Thus for the proper economic growth that will support both industrial and domestic activities there is a strong need for the sufficient energy consumption to carter the need for proper development then the total energy consumption should be greater or equal to the average annual energy consumption needed in the given period of time for the proper economic growth. The average annual sum of all energy consumption is 24769.8 units of energy.

$$
z_{1}+z_{2}+z_{3}+z_{4}+z_{5}+z_{6} \geq 24769.8
$$


Also the total energy consumption should be equal or less than the available energy (energy produced), then:

$$
z_{1}+z_{2}+z_{3}+z_{4}+z_{5}+z_{6} \leq y_{1}+y_{2}+y_{3}+y_{4}+y_{5}+y_{6}
$$

This is equal to;

$$
z_{1}+z_{2}+z_{3}+z_{4}+z_{5}+z_{6}-y_{1}-y_{2}-y_{3}-y_{4}-y_{5}-y_{6} \leq 0
$$

(j) Boundary constraint As we reduce the effects to the environment as a result of energy activities we need to incorporate clean and renewable energy to the general composition of energy system in Tanzania. Then the study suggest that the harvesting, production and consumption of clean and renewable energies like Natural gas, Renewable (Wind, solar, geothermal) and electricity should be at least $20 \%$ of the total energy then;

$x_{2}, x_{3}, x_{4} \geq 7474, y_{2}, y_{3}, y_{4} \geq 8259$ and $z_{2}, z_{3}, z_{4} \geq 1268$

(k) Non-negative constraints

$X_{i}(t) \geq 0, Y_{i}(t) \geq 0$ and $Z_{i}(t)$

\section{Mathematical analysis}

Using Zimmermann modified method as analyzed in the papers by [24] and [25], we solve the multi-objective linear programming problem as a single objective linear programming problem by using any linear programming algorithm, considering only one of the objectives at a time The mathematical multi-objective optimization model in the real plane may be presented as follows

We want to find $X=\left(x_{1}, \ldots, x_{n}\right), Y=\left(y_{1}, \ldots, y_{n}\right)$ and $Z=\left(z_{1}, \ldots, z_{n}\right)$

So that

$$
\operatorname{Min} F=\sum_{i=1}^{m} \sum_{j=1}^{n}\left(a_{j} X_{i}+b_{j} Y_{i}+c_{j} Z_{j}\right)
$$

subject to;

$$
\left\{\begin{array}{l}
D_{k} \geq d_{k} \\
U_{k} \geq u_{k} \\
Q_{k} \geq q_{k} \\
R_{1} \geq r_{1} \\
R_{2} \geq r_{2} \\
R_{3} \geq r_{3}
\end{array}\right.
$$

We assume the variables set of $X, Y$ and $Z$ and the objective constraints $D_{k}, U_{k}, Q_{k}$ and $R_{k}$ are in fuzzy domain and they are the triangular numbers we use them in the transformation of the original problem, which is a fuzzy problem, into a clear linear programming problem.

\subsection{Zimmermann modified method algorithm}

In the paper by [24] they analyzed five important steps to follow when using Zimmermann modified method to solve problem and in our case we will customize it as given below ; 
Step-1. Define the membership function corresponding to the variables $X, Y$ and $Z$.

$$
\begin{gathered}
\mu_{x_{i}}(X)=\left\{\begin{array}{l}
0 \text { if } x_{i}<\underline{x_{i}} \\
\overline{x_{i}-x_{i}} \\
\overline{x_{i}-\underline{x_{i}}} \text { if } \underline{x_{i}}<x_{i}<\overline{x_{i}} \\
1 \text { if } \bar{x}_{i}>\overline{x_{i}}
\end{array}\right. \\
\mu_{y_{i}}(Y)=\left\{\begin{array}{l}
0 \text { if } y_{i}<\underline{y_{i}} \\
\frac{\overline{y_{i}}-y_{i}}{y_{i}-\underline{y_{i}}} \text { if } \underline{y_{i}}<y_{i}<\overline{y_{i}} \\
1 \text { if } y_{i}>\overline{y_{i}}
\end{array}\right. \\
\mu_{z_{i}}(Z)=\left\{\begin{array}{l}
0 \text { if } z_{i}<\underline{z_{i}} \\
\overline{z_{i}-z_{i}} \\
\overline{z_{i}-\underline{z_{i}}} \\
1 \text { if } \underline{z_{i}}<z_{i}>z_{i}<\overline{z_{i}}
\end{array}\right.
\end{gathered}
$$

Step-2. Use $\alpha-$ cut to make the fuzzy system to crisp and use general method to solve the system.

That is for any

$$
\begin{array}{lll}
\alpha \in[0,1] & \alpha \in[0,1] & \alpha \in[0,1] \\
\frac{\bar{x}_{i}-x_{i}}{x_{i}-\underline{x_{i}}}=\alpha & \frac{\bar{y}_{i}-y_{i}}{y_{i}-\underline{y_{i}}}=\alpha & \frac{\overline{z_{i}}-z_{i}}{z_{i}-\underline{z_{i}}}=\alpha
\end{array}
$$

Step-3. Using this $\alpha$-cut we transform the original linear programming problem, which is a fuzzy problem, into a clear linear programming problem by introducing the parameter $\alpha$.

Modifying the given objectives the objective function now become;

$$
\operatorname{Min} F=\sum_{i=1}^{6} \sum_{j=1}^{6} a_{j} X_{i}+\sum_{i=1}^{6} \sum_{j=1}^{6} b_{j} Y_{i}+\sum_{i=1}^{6} \sum_{j=1}^{6} c_{j} Z_{j}
$$

On transforming the fuzzy into a clear linear programming equation we can write $a_{j}, b_{j}$ and $c_{j}$ in the following

$$
a_{j}=\left[\underline{a_{j}} ; a_{j} ; \overline{a_{j}}\right], b_{j}=\left[\underline{b_{j}} ; b_{j} ; \overline{b_{j}}\right] \text { and } c_{j}=\left[\underline{c_{j}} c_{j} ; \overline{c_{j}}\right]
$$

Then using the triangular fuzzy number rule the formula and applying difuzzification method the linear programming problem becomes;

$$
\begin{aligned}
\operatorname{Min} F= & \left(\sum_{i=1}^{6} \sum_{j=1}^{6} a_{j} X_{i}-\alpha\left(\sum_{i=1}^{6} \sum_{j=1}^{6} a_{j} X_{i}+\sum_{i=1}^{6} \sum_{j=1}^{6} a_{j} X_{j}\right)\right) \\
& +\left(\sum_{i=1}^{6} \sum_{j=1}^{6} b_{j} Y_{i}-\alpha\left(\sum_{i=1}^{6} \sum_{j=1}^{6} b_{j} Y_{i}+\sum_{i=1}^{6} \sum_{j=1}^{6} b_{j} Y_{j}\right)\right) \\
& +\left(\sum_{i=1}^{6} \sum_{j=1}^{6} c_{j} Z_{i}-\alpha\left(\sum_{i=1}^{6} \sum_{j=1}^{6} c_{j} Z_{i}+\sum_{i=1}^{6} \sum_{j=1}^{6} c_{j} Z_{j}\right)\right)
\end{aligned}
$$

where $\alpha \in[0,1]$. Then we consider the objective constraints and follow the same defuzzification procedure of

$$
D_{k} \geq d_{k}, U_{k} \geq u_{k}, Q_{k} \geq q_{k}, R_{1} \geq r_{1}, R_{2} \geq r_{2}, R_{3} \geq r_{3}
$$


$D_{k}, U_{k}, Q_{k}, R_{k}$ are triangular fuzzy numbers then, $-D_{k} \leq-d_{k}$ and since it is a triangular fuzzy number we will have $-D_{k}=\left[-d_{k} ;-d_{k} ;-\bar{d}_{k}\right]$ Introducing the parameter $\alpha$ then the above function can be transformed into $\left.-D_{k} \leq-\bar{d}_{k}-\alpha \overline{(}_{k}-\bar{d}_{k}\right) \quad \alpha \in[0,1]$. This is equal to; $D_{k} \geq \bar{d}_{k}+\alpha\left(d_{k}-\bar{d}_{k}\right) \alpha \in[0,1]$. Now using the same method the diffuzzification of other constraint will be;

$$
\begin{aligned}
& U_{k} \geq \overline{u_{k}}+\alpha\left(u_{k}-\overline{u_{k}}\right) \alpha \in[0,1] \\
& Q_{k} \geq \overline{q_{k}}+\alpha\left(q_{k}-\overline{q_{k}}\right) \alpha \in[0,1] \\
& R_{k} \geq \overline{r_{k}}+\alpha\left(r_{k}-\overline{r_{k}}\right) \alpha \in[0,1]
\end{aligned}
$$

The distribution of parameter $\alpha$ provide the way of measuring possibility and reliability of decision risk in order to achieve equilibrium compromise between target value and possible value. The value of $\alpha$ it turns the complicated fuzzy linear programming problem into a clear problem.

Step-4. By putting $\alpha=0$ and $\alpha=1$ we obtain the lower bound $\underline{X_{i}}, \underline{Y_{i}}, \underline{Z_{i}}$, and the upper bound $\bar{X}_{i}, \bar{Y}_{i}, \bar{Z}_{i}$ of the optimal solution of this linear programming problem.

Step-5. Get the optimal solution of the linear programming model by average of the lower and the upper bound of the solution. Similarly, by taking the average of the point we get the point where optimal solution will exist.

\subsection{Model optimization}

We want to find $X=\left(x_{i}, x_{2}, x_{3}, x_{4}, x_{5}, x_{6}\right), Y=\left(y_{i}, y_{2}, y_{3}, y_{4}, y_{5}, y_{6}\right)$ and $Z=\left(z_{i}, z_{2}, z_{3}, z_{4}, z_{5}, z_{6}\right)$ So as to Minimize the total pollution load $\left(\mathrm{MtCO}_{2} e\right)$ as a result of energy production, harvesting and consumption.

$$
\begin{array}{r}
\operatorname{Min} F= \\
a_{1}\left((1-\alpha) x_{1}+\alpha x_{1}\right)+a_{2}\left((1-\alpha) x_{2}+\alpha x_{2}\right)+a_{3}\left((1-\alpha) x_{3}+\alpha x_{3}\right)+a_{4}\left((1-\alpha) x_{4}+\alpha x_{4}\right) \\
+a_{5}\left((1-\alpha) x_{5}+\alpha x_{5}\right)+a_{6}\left((1-\alpha) x_{6}+\alpha x_{6}\right)+b_{1}\left((1-\alpha) y_{1}+\alpha y_{1}\right)+b_{2}\left((1-\alpha) y_{2}+\alpha y_{2}\right) \\
+b_{3}\left((1-\alpha) y_{3}+\alpha y_{3}\right)+b_{4}\left((1-\alpha) y_{4}+\alpha y_{4}\right)+b_{5}\left((1-\alpha) y_{5}+\alpha y_{5}\right)+b_{6}\left((1-\alpha) y_{6}+\alpha y_{6}\right) \\
+c_{1}\left((1-\alpha) z_{1}+\alpha z_{1}\right)+c_{2}\left((1-\alpha) z_{2}+\alpha z_{2}\right)+c_{3}\left((1-\alpha) z_{3}+\alpha z_{3}\right)+c_{4}\left((1-\alpha) z_{4}+\alpha z_{4}\right) \\
+c_{5}\left((1-\alpha) z_{5}+\alpha z_{5}\right)+c_{6}\left((1-\alpha) z_{6}+\alpha z_{6}\right)
\end{array}
$$

Subject to the above inequality constraints.

\section{Numerical results}

Then, following Zimmermann modified method algorithm, using mat lab we solve the optimization problem and as we change the value of $\alpha$ results are as follows;

Table 1: Optimal Solution when $\alpha=0$

\begin{tabular}{|c|c|}
\hline \multicolumn{2}{|c|}{ Energy Harvest } \\
\hline Variable & Value \\
\hline$x_{1}$ & 0 \\
\hline$x_{2}$ & 7474 \\
\hline$x_{3}$ & 7474 \\
\hline$x_{4}$ & 7474 \\
\hline$x_{5}$ & 269 \\
\hline$x_{6}$ & 0 \\
\hline
\end{tabular}

\begin{tabular}{|c|c|}
\hline \multicolumn{2}{|c|}{ Energy Production } \\
\hline Variable & Value \\
\hline$y_{1}$ & 0 \\
\hline$y_{2}$ & 8259 \\
\hline$y_{3}$ & 8257 \\
\hline$y_{4}$ & 8259 \\
\hline$y_{5}$ & 309 \\
\hline$y_{6}$ & 0 \\
\hline
\end{tabular}

\begin{tabular}{|c|c|}
\hline \multicolumn{2}{|c|}{ Energy Consumption } \\
\hline Variable & Value \\
\hline$z_{1}$ & 0 \\
\hline$z_{2}$ & 1887 \\
\hline$z_{3}$ & 1887 \\
\hline$z_{4}$ & 21617 \\
\hline$z_{5}$ & 0 \\
\hline$z_{6}$ & 0 \\
\hline
\end{tabular}


Table 2: Optimal Solution when $\alpha=1$

\begin{tabular}{|c|c|}
\hline \multicolumn{2}{|c|}{ Energy Harvest } \\
\hline Variable & Value \\
\hline$x_{1}$ & 0 \\
\hline$x_{2}$ & 7470 \\
\hline$x_{3}$ & 7470 \\
\hline$x_{4}$ & 7470 \\
\hline$x_{5}$ & 268 \\
\hline$x_{6}$ & 0 \\
\hline
\end{tabular}

\begin{tabular}{|c|c|}
\hline \multicolumn{2}{|c|}{ Energy Production } \\
\hline Variable & Value \\
\hline$y_{1}$ & 0 \\
\hline$y_{2}$ & 8256 \\
\hline$y_{3}$ & 8254 \\
\hline$y_{4}$ & 8256 \\
\hline$y_{5}$ & 308 \\
\hline$y_{6}$ & 0 \\
\hline
\end{tabular}

\begin{tabular}{|c|c|}
\hline \multicolumn{2}{|c|}{ Energy Consumption } \\
\hline Variable & Value \\
\hline$z_{1}$ & 0 \\
\hline$z_{2}$ & 1896 \\
\hline$z_{3}$ & 1264 \\
\hline$z_{4}$ & 21608 \\
\hline$z_{5}$ & 0 \\
\hline$z_{6}$ & 0 \\
\hline
\end{tabular}

Hence the Optimal solution that minimizes the pollution load to the environment occurs at the variable values as displayed in the table below;

Table 3: General solution for minimization of environment pollutants

\begin{tabular}{|c|c|}
\hline \multicolumn{2}{|c|}{ Energy Harvest } \\
\hline Variable & Value \\
\hline$x_{1}$ & 0 \\
\hline$x_{2}$ & 7472 \\
\hline$x_{3}$ & 7472 \\
\hline$x_{4}$ & 7472 \\
\hline$x_{5}$ & 268 \\
\hline$x_{6}$ & 0 \\
\hline
\end{tabular}

\begin{tabular}{|c|c|}
\hline \multicolumn{2}{|c|}{ Energy Production } \\
\hline Variable & Value \\
\hline$y_{1}$ & 0 \\
\hline$y_{2}$ & 8258 \\
\hline$y_{3}$ & 8258 \\
\hline$y_{4}$ & 8263 \\
\hline$y_{5}$ & 309 \\
\hline$y_{6}$ & 0 \\
\hline
\end{tabular}

\begin{tabular}{|c|c|}
\hline \multicolumn{2}{|c|}{ Energy Consumption } \\
\hline Variable & Value \\
\hline$z_{1}$ & 0 \\
\hline$z_{2}$ & 1892 \\
\hline$z_{3}$ & 1576 \\
\hline$z_{4}$ & 21613 \\
\hline$z_{5}$ & 0 \\
\hline$z_{6}$ & 0 \\
\hline
\end{tabular}

\section{Analysis of results}

The linear programming problem presented above with the aim of minimizing environment pollutants has been solved by mat lab following the Zimmermann modified method algorithm. The optimal values of the decisive variable that minimizes the environment pollutants from different energy activities $X=\left(x_{1}, \ldots, x_{6}\right), Y=\left(y_{1}, \ldots, y_{6}\right)$ and $Z=\left(z_{1}, \ldots, z_{6}\right)$ shown in the section above are presented graphically as shown in the figure bellow; The result shows the enormous decrease of various energy activities (harvesting, production and consumption) that has large environmental effects like coal, Biomass and Oil. There is however the significant improvement of energy activities from renewable and clean energies that are natural gas, renewable and electricity. This energy structure composition gives the wide margin for improving the Tanzania?s energy structure to stop depending on the biomass (Wood fuel and charcoal) and oil and considerably let the renewable and clean energies take over in order to reduce the effect caused to the environment.

\section{Conclusion}

This work has introduced the mathematical model for minimizing environment pollutants as a result of different energy activities specifically energy production, harvesting and consumption. The problem has been considered as a linear programming problem that account for minimization of environmental pollutants. The Zimmerman modified method has been employed in order to expedite the solution of such model. The result discussed in this study will be the doorway for Tanzania to realize her development vision 2025 sustainably with the clean and safe environment. 


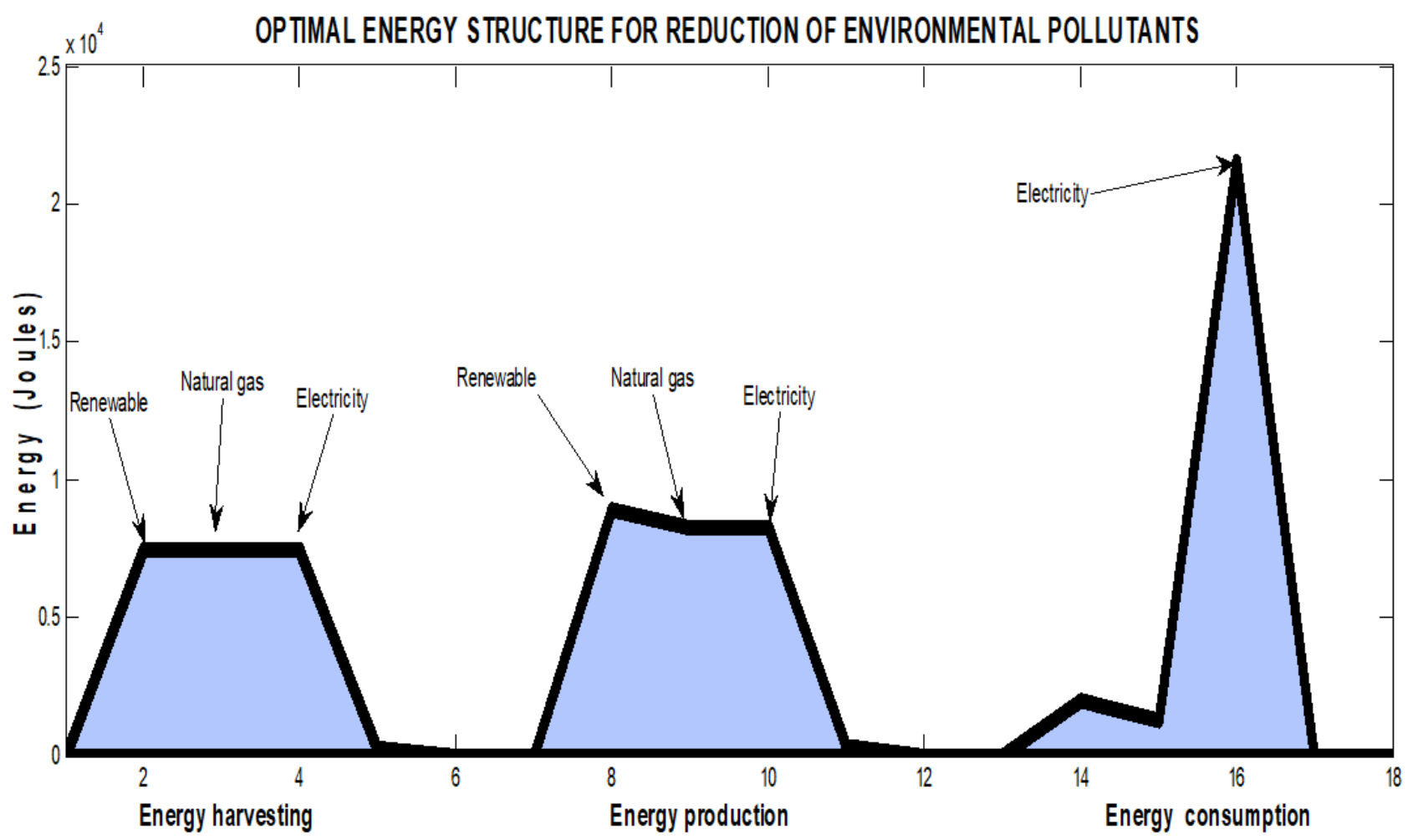

Fig. 3: Optimal energy structure composition for reduction of environmental pollutant

We therefore would like to stress importance of bringing the outcome of this study to the attention of those who are responsible for environment issues in order to improve the ways and methods they are using to protect the environment. It is important this knowledge to be communicated to the people of Tanzania as they are the primary stakeholders when comes to energy utilization. We also encourage decision makers to use the studies like this when making decision for the good reason of achieving the goals of Tanzania development vision 2025.

\section{Competing interests}

The authors declare that they have no competing interests.

\section{Authors' contributions}

All authors have contributed to all parts of the article. All authors read and approved the final manuscript.

\section{References}

[1] I. Dincer, "Energy and environmental impacts: Present and future perspectives," Energy Sources, 1998.

[2] R. Kangalawe, “UNITED REPUBLIC OF TANZANIA,” Consultant, 2012.

[3] F. Gwang?ombe, "Renewable energy technologies in Tanzania," Dar-Es-Salaam Tanzania PP25, 2004.

[4] G. A. Mackenzie, J. K. Turkson, and O. R. Davidson, "Climate change mitigation in Africa," 1998.

[5] F. Umbach, "Nuclear energy issues-global dimensions and security challenges," 2003. 
[6] F. Froehlich, I. M. W. Ostrowski, and I. F. W. Mtalo, "Application of the TALSIM 2.0 model on the Mtera-Kidatu Reservoir System in the Rufiji River Basin in Southern Tanzania," PhD diss., Tech. Univ. Darmstadt, 2001.

[7] J. O. and others Mwazembe, "Green renewable private power production in Tanzania," 2011.

[8] W. Bank, "Reports on Tanzania Energy Situation,” 2018.

[9] W. Xiaohua, D. Xiaqing, and Z. Yuedong, "Domestic energy consumption in rural China: A study on Sheyang County of Jiangsu Province," Biomass and Bioenergy, 2002.

[10] M. C. Tandari, “The Tanzania development vision 2025,” Dear Partners, Friends \& Interest. Readers, p. 63 , 1999.

[11] L. H. Mosha, "Renewable energy policy issues in human settlements-The case of Tanzania," in workshop of Promoting Renewable Energy in Africa, Dar es Salaam, Tanzania, 2007.

[12] T. W. Luke, "Placing Ecocritique in Context: Technology, Democracy and Capitalism as Environment," in Association for the Study of Literature and Environment, 1999.

[13] R. Bryce, "Gusher of Lies: The Dangerous Delusions of Energy Independence”. PublicAffairs, 2008.

[14] A. M. Omer, "Energy use, environment and sustainable development," in Environmental Cost Management, 2009.

[15] J. Goldemberg and O. Lucon, Energy, environment and development. 2010.

[16] J. P. Holdren, K. R. Smith, T. Kjellstrom, D. Streets, X. Wang, and S. Fischer, "Energy, the environment and health,” New York United Nations Dev. Program., 2000.

[17] L. A. Greening, D. L. Greene, and C. Difiglio, "Energy efficiency and consumption?the rebound effect?a survey," Energy Policy, vol. 28 , no. $6 ? 7$, pp. $389 ? 401,2000$.

[18] T. H. Tietenberg and L. Lewis, "Environmental and natural resource economics". Routledge, 2016.

[19] C. J. Cho, "The economic-energy-environmental policy problem: An application of the interactive multiobjective decision method for Chungbuk Province,” J. Environ. Manage., 1999.

[20] R. J. Utz, "Sustaining and sharing economic growth in Tanzania". The World Bank, 2007.

[21] M. T. Rock, "The stork, the plow, rural social structure and tropical deforestation in poor countries?," Ecol. Econ., vol. 18, no. 2, pp. 113-131, 1996.

[22] J. A. Sathaye et al., "Carbon mitigation potential and costs of forestry options in Brazil, China, India, Indonesia, Mexico, the Philippines and Tanzania," Mitigation and Adaptation Strategies for Global Change. 2001.

[23] A. Mwakapugi, W. Samji, and S. Smith, "The Tanzanian energy sector: The potential for job creation and productivity gains through expanded electrification," Res. Poverty Alleviation, 2010.

[24] S. K. Behera and J. R. Nayak, "Solution of multi-objective mathematical programming problems in fuzzy approach," Int. J. Comput. Sci. Eng., vol. 3, no. 12, p. 3790, 2011.

[25] M. R. Safi, H. R. Maleki, and E. Zaeimazad, “A note on the zimmermann method for solving fuzzy linear programming problems," Iran. J. Fuzzy Syst., 2007. 